\title{
CHROMOSOME PULVERIZATION IN CHINESE HAMSTER MULTINUCLEATE CELLS INDUCED BY BLEOMYCIN AND CYTOCHALASIN B1)
}

\author{
TATSURO IKEUCHI \\ Chromosome Research Unit, Faculty of Science, \\ Hokkaido University, Sapporo 060
}

Received September 25, 1973

\section{INTRODUCTION}

The so-called chromosome pulverization phenomenon in multinucleate cells has been studied with various cell-virus systems (cf. Sandberg et al. 1970; Johnson and Rao 1971). It is generally accepted that the phenomenon is induced in interphase nuclei by coexisting, as a result of virus-induced cell fusion, with a set of normal metaphase chromosomes in a common cytoplasm. Spontaneous chromosome pulverization has also been observed in several mammalian cell lines (Kato and Sandberg 1967, 1968; Miles and O’Neill 1969; O’Neill and Miles 1971), some of which were persistently infected with certain viruses.

Recent morphological and biochemical studies with Sendai virus-fused cells revealed that the process leading to this phenomenon simulates very closely the nuclear changes occurring in normal transition from G2 to mitotic stage (Aya and Sandberg 1971; Stenman 1971; Matsui et al. 1972a); thus the phenomenon of "chromosome pulverization" originally termed by Nichols et al. (1964) has been explained as the nuclear event sequential to the premature occurrence of chromatin condensation (Johnson and Rao 1970; Stenman 1971) or more comprehensively to the induction of prophase (Matsui et al. 1972a). Hence the term "prophased or pulverized chromatin" (PC) will be used hereafter.

Since the PC-inducing factor(s) are probably normal cellular components present in the mitotic nucleus and/or its cytoplasm rather than the virus itself (Sandberg et al. 1970; Ikeuchi and Sandberg 1970; Ikeuchi et al. 1971; Matsui et al. 1971), it is reasonable to assume that the phenomenon could occur in multinucleate cells produced by non-viral agents. Recently, chromatin changes equivatent to PC were observed in multinucleate cells induced by tritiated thymidine (Ikeuchi et al. 1972) and cytochalasin B (O’Neill 1972).

The present study deals with micronucleate and multinucleate cells produced by bleomycin and cytochalasin B, with particular attention to the morphologic aspects of $\mathrm{PC}$ in relation to the nuclear asynchrony as revealed by autoradiographic cell cycle study.

1) Presented to the Faculty of Science, Hokkaido University, in partial fulfilment of the requirements for the degree of Doctor of Science, March 1972. 


\section{MATERIALS AND METHODS}

Cells: Two established Chinese hamster cell lines, $\mathrm{CH}-\mathrm{Cl}_{2}$ and Don, were used. $\mathrm{CH}-\mathrm{Cl}_{2}$ is a clone isolated by Dr. M. C. Yoshida from a fibroblastic cell line $\mathrm{CH}$ which was established by Drs. M. Sasaki and M. Mori from the spleen of a male. It has a modal chromosome number of 27 , with no detectable marker chromosomes. Don was kindly supplied by Dr. A. A. Sandberg of the Roswell Park Memorial Institute, Buffalo, U.S.A. It is a pseudodiploid cell line with a modal number of 22 chromosomes. Both cell lines have been maintained in this laboratory as a monolayer culture in Eagle's minimum essential medium (MEM) supplemented with $10 \%$ fetal calf serum.

Chemicals: Bleomycin (BLM) is an antitumor antibiotic (Umezawa et al. 1967). It induces chromosome aberrations (Paika and Krishan 1973) leading to the production of micronuclei in the progeny cells, as in a similar way to certain chemicals (Arora et al. 1969) or ionizing radiations (Das 1962; Ikeuchi et al. 1972). BLM (Nihon Kayaku Co., Ltd., Tokyo) was dissolved in MEM immediately before use.

Cytochalasin $\mathrm{B}(\mathrm{CB})$ is a fungal metabolite which inhibits cytokinesis without affecting karyokinesis resulting in multinucleate cell formation (Carter 1967; Krishan and Ray-Chaudhuri 1969). CB (The I.C.I. Res. Lab., Cheshire, England) was dissolved in the minimum volume of dimethylsulfoxide (DMSO), diluted with MEM to give a final concentration of $100 \mu \mathrm{g} / \mathrm{ml}$, and stored frozen at $-20^{\circ} \mathrm{C}$.

Preparation of cells and autoradiography: Slides for chromosomal and cytological observations were prepared as described previously (Ikeuchi and Sandberg 1970). The cells, unless otherwise stated, were treated with Colcemid $(0.1 \mu \mathrm{g} / \mathrm{ml})$ for the final 2 hours of culture. For autoradiography, cultured cells were exposed to ${ }^{3} \mathrm{H}$-thymidine $\left({ }^{3} \mathrm{H}-\mathrm{TdR}\right.$, specific activity $10.0 \mathrm{Ci} / \mathrm{mmole}$, Daiichi Pure Chemicals Co., Ltd., Tokyo) at a final concentration of $1.0 \mu \mathrm{Ci} / \mathrm{ml}$ for either 20 minutes or 2.5 hours. The cells were then harvested, and the slides were coated with Sakura NR-M2 emulsion. After exposure at $4^{\circ} \mathrm{C}$ for 7 to 10 days, they were processed in either Kodak D-19 or Sakura Conidol-X developer, and stained with Giemsa. When necessary, the slides stained with Giemsa before coating were destained with $50 \%$ acetic acid, processed for autoradiography, and restained with Giemsa.

\section{RESULTS}

1. Bleomycin experiments.

Micronucleation and $P C$ induction: $\mathrm{CH}-\mathrm{Cl}_{2}$ cells were used throughout the BLM experiments. When the cells were exposed to various concentrations of BLM $(0.5-10.0$ $\mu \mathrm{g} / \mathrm{ml}$ ), the mitotic index decreased slightly and several types of chromosome aberrations were observed, both being dose dependent (Table 1). The aberrations consisted of breaks (both chromatid and isochromatid-types), fragments, dicentrics, multiradials and endoreduplication (Figs. 3 and 4). Among them, breaks and fragments were predominant.

Careful examination revealed some metaphase cells involving one or a few unusually 
condensed and/or clumped chromatins conglomerating in a restricted area of a metaphase plate (Figs. 5-7). Morphologically they were equivalent to PC observed in virusfused cells. The affected chromatin was assumed to be derived from micronuclei as evinced previously (Kato and Sandberg 1968; Ikeuchi et al. 1972). In fact, a number of cells having one or more small nuclei of different sizes was noticed in the BLM-treated cells (Figs. 9 and 10). These micronuclei probably represent lagging chromosomes or acentric fragments extruded from the equatorial plate in the preceding division (Fig. 8). The percentages of both micronucleate cells and cells with PC increased significantly in parallel with the exposure time and concentration of BLM, though the increment of PC occurred with 1-2 days of delay after the appearance of micronucleate cells (Fig. 1).
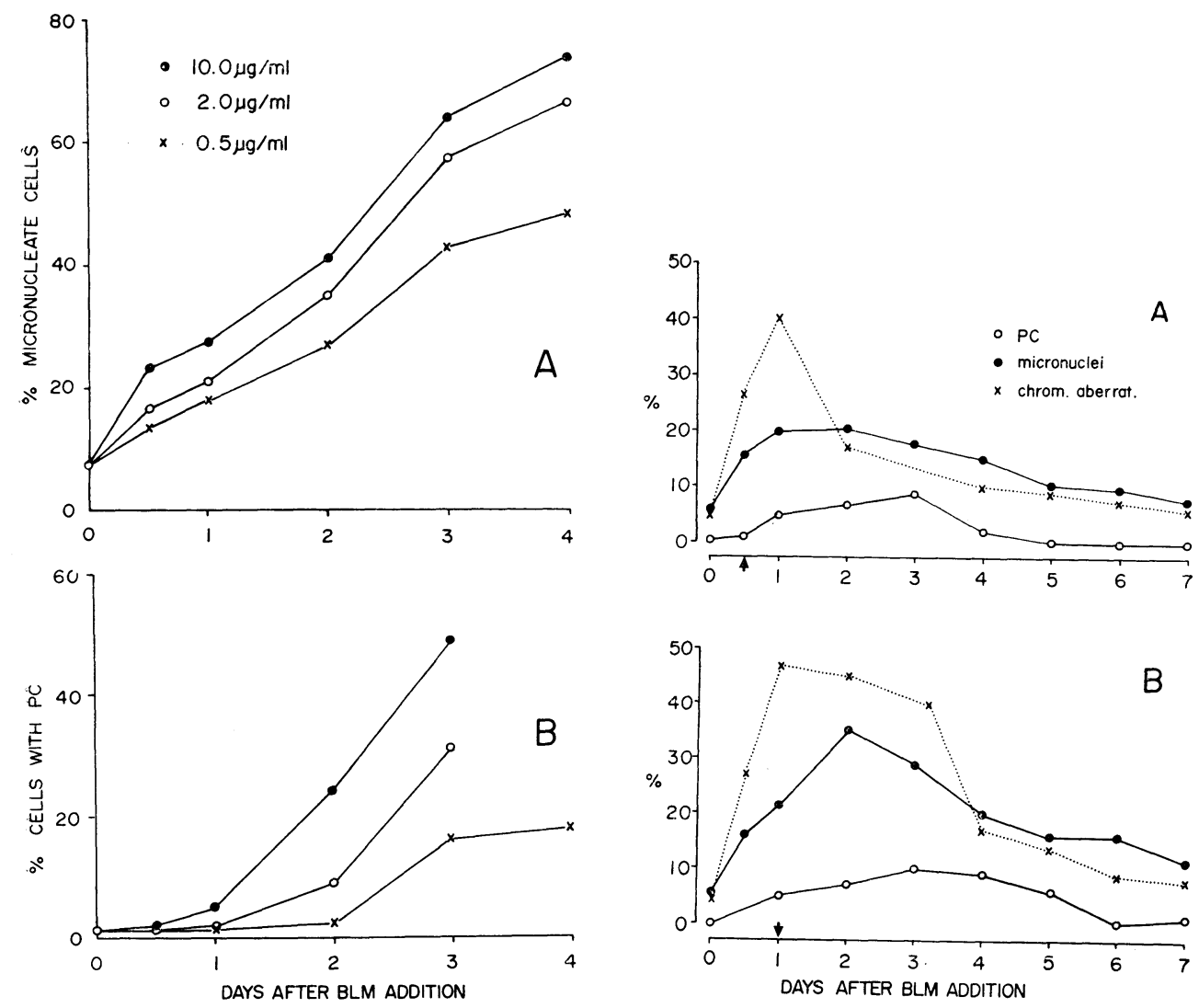

Fig. 1. Percentages of micronucleate cells (Part A) and of metaphase cells with PC (Part B) after addition of BLM.

Fig. 2. Percentages of cells with chromosome aberrations, micronuclei and $\mathrm{PC}$ after removal of BLM. Arrows indicate the time when BLM was removed.

The cells treated with BLM $(2.0 \mu \mathrm{g} / \mathrm{ml})$ for 12 or 24 hours were transferred to the drug-free medium and their recovery stages were followed daily until one week after the treatment (Fig. 2). The incidence of chromosome aberrations continued to increase during the first 12-24 hours of recovery, then it showed a sharp decline in a subsequent period, while the micronucleate cells still continued to increase until the 2nd day 
and the PC cells until the 3rd or 4th day after BLM addition.

Autoradiographic study: The cells treated with BLM for 3 days at a concentration of $2 \mu \mathrm{g} / \mathrm{ml}$ were exposed to ${ }^{3} \mathrm{H}-\mathrm{TdR}$ and Colcemid simultaneously for 2.5 hours. The affected chromatin were arbitrarily classified into the following three types according to their morphology. Type A: string-like chromatin which appeared eroded or incompletely condensed single-strand chromatid (Fig. 5). Type B: chromosomes of unusually extended appearance, showing segmented structures in some cases (Fig. 6). Type C: finely scattered chromatin particles (Fig. 7).

Labeling patterns of the three different types of PC are presented in Table 2, together with those in $\mathrm{CB}$ experiments to be described later. All of the type $\mathrm{B}$ and about $40 \%$ of the type $\mathrm{C}$ chromatin were apparently labeled (Fig. 7), but no labeling was observed in the type A chromatin. The normal metaphase chromosomes in the same cells were entirely unlabeled or only slightly labeled, suggesting the existence of asynchronous DNA synthesis between the PC and normal chromosomes.

Incidentally, the extremely fragmented chromosomes (Fig. 4), occasionally seen in cells treated for longer periods of time, were not labeled after the present exposure time. Although this abnormality is somewhat similar in morphology to the type $\mathrm{C}$, the processes involved in the two phenomena seemed essentially different.

Table 1. Incidences of chromosome aberrations and mitotic indexes after treatment with BLM at various concentrations

\begin{tabular}{|c|c|c|c|c|}
\hline \multirow{3}{*}{$\begin{array}{c}\text { Conc. of BLM } \\
(\mu \mathrm{g} / \mathrm{ml})\end{array}$} & \multicolumn{4}{|c|}{ Duration of exposure time } \\
\hline & \multicolumn{2}{|c|}{24 hours } & \multicolumn{2}{|c|}{54 hours } \\
\hline & $\underset{(\%)^{1)}}{\text { Chrom. }}$ & $\begin{array}{l}\text { Mitotic index } \\
(0 / 00)\end{array}$ & $\begin{array}{c}\text { Chrom. aberrat. } \\
(\%)^{1)}\end{array}$ & $\begin{array}{c}\text { Mitotic index } \\
(\% / 00)\end{array}$ \\
\hline 0.0 & 5.1 & 18 & 4.3 & 17 \\
\hline 0.5 & 38.4 & 15 & 74.0 & 16 \\
\hline 1.0 & 45.6 & 12 & 79.0 & 17 \\
\hline 5.0 & 68.0 & 12 & 82.3 & 12 \\
\hline 10.0 & 75.8 & 10 & 92.0 & 6 \\
\hline
\end{tabular}

1) Based on $100-500$ metaphases.

The patterns of DNA synthesis in interphase micronucleate cells were examined on the basis of a total of 130 labeled cells with a main- and a micronucleus. The following three categories were exhibited: $53.9 \%$ of the cells had the label in both main- and micronuclei (Fig. 9), in $38.4 \%$ the label was localized only in the main nucleus, while in the remaining $7.7 \%$ it was restricted to the micronuclei (Fig. 10). This indicates asynchronous DNA synthesis between the main- and micronuclei, though some micronuclei might have no ability of DNA synthesis in themselves (Das 1962; Arora et al. 1969).

2. Cytochalasin B experiments.

Multinucleation and PC induction: Don cells were used. The exposure of Don cells to $\mathrm{CB}$ at a concentration of $1.0 \mu \mathrm{g} / \mathrm{ml}$ showed a striking increase in frequency of 

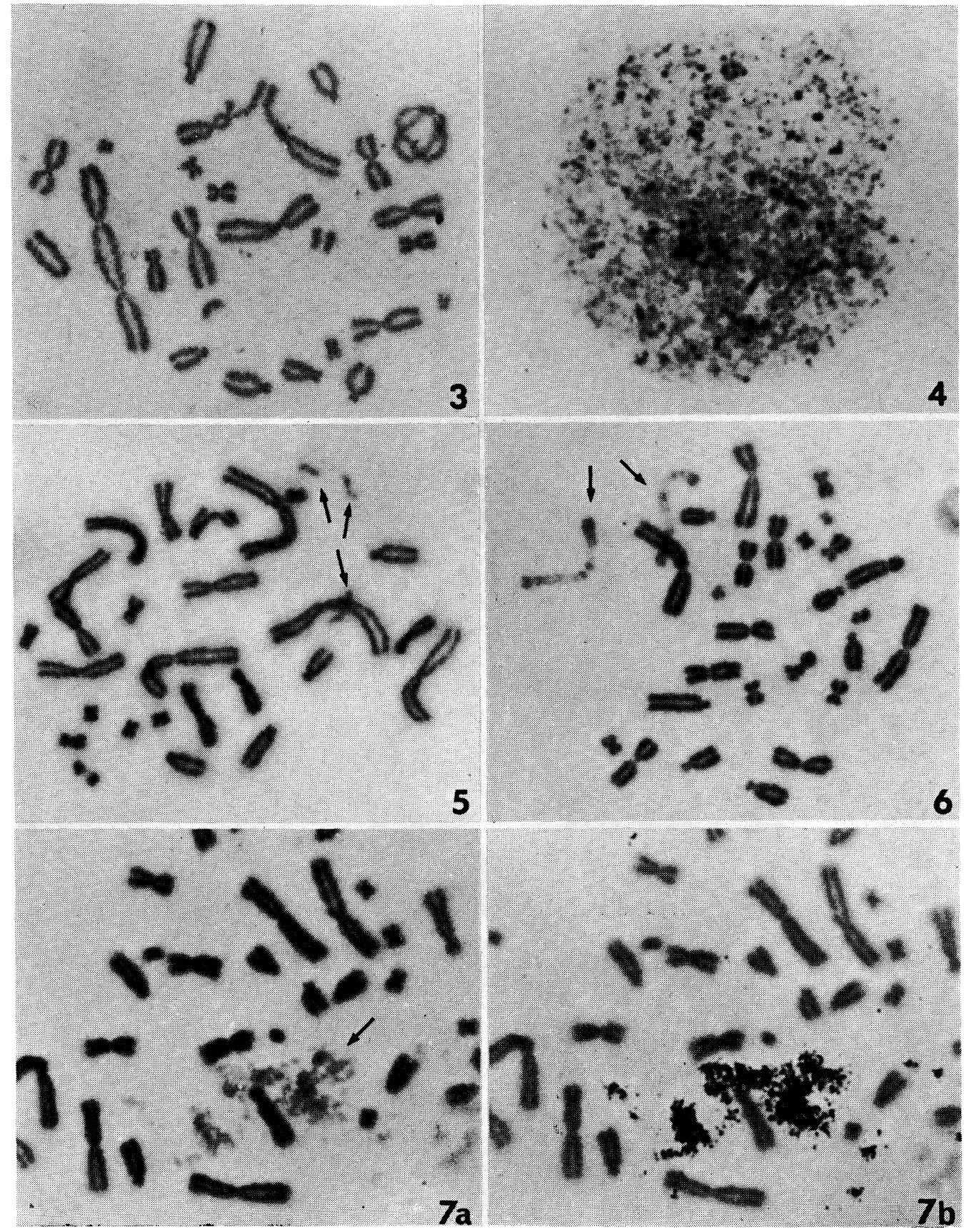

Fig. 3-4. $\mathrm{CH}-\mathrm{Cl}_{2}$ cells with various kinds of chromosome aberrations produced by treatment with BLM $(2 \mu \mathrm{g} / \mathrm{ml})$ for 12 hours. 3. Cell with chromosome breaks, fragments, ring and dicentric chromosomes. 4. Cell showing an extreme type of chromosome fragmentation.

Fig. 5-7. $\mathrm{CH}-\mathrm{Cl}_{2}$ metaphase cells with various types of $\mathrm{PC}$ (indicated by arrows) produced by BLM treatment $(2 \mu \mathrm{g} / \mathrm{ml})$ for 3 days. a) before autoradiography; b) after autoradiography. 5. Type A. 6. Type B. 7. Type C. 


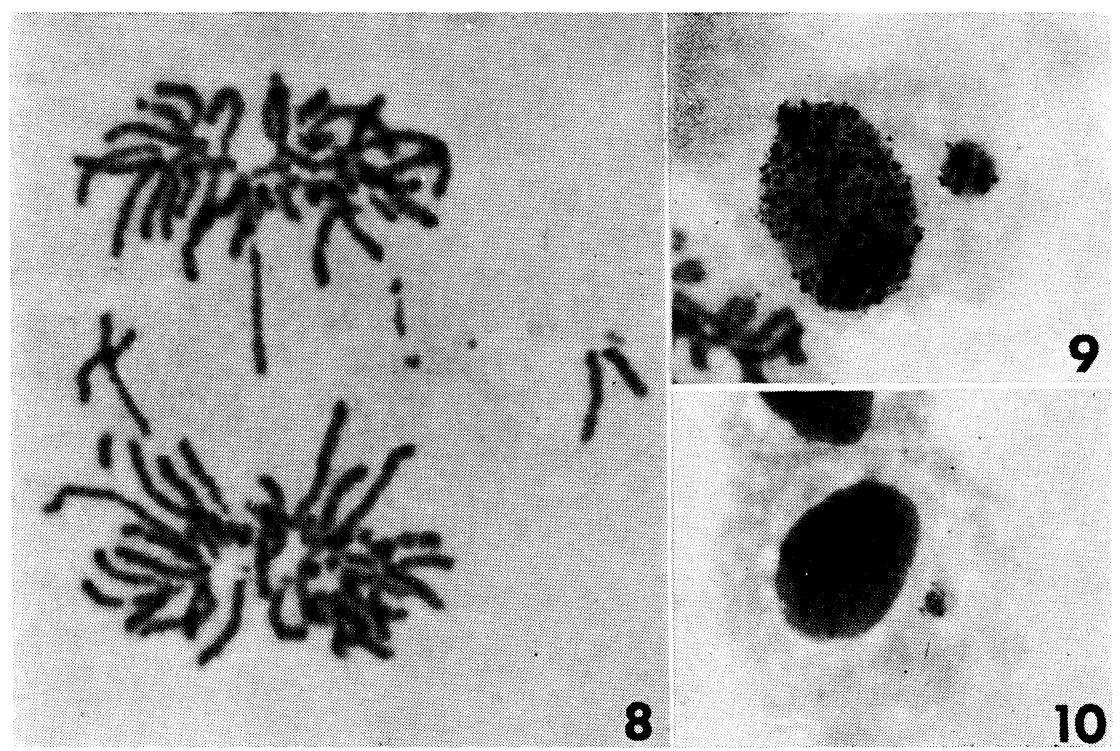

Fig. 8. An example of abnormal cell division showing chromosome bridges, lagging chromosomes and fragments.

Figs. 9-10. Autoradiographs of BLM-induced micronucleate cells after exposure to ${ }^{3} \mathrm{H}-\mathrm{TdR}$ for 2.5 hours. 9. Cell in which both the mainand micronuclei are labeled. 10. Cell in which the label was localized on the micronuclei alone.

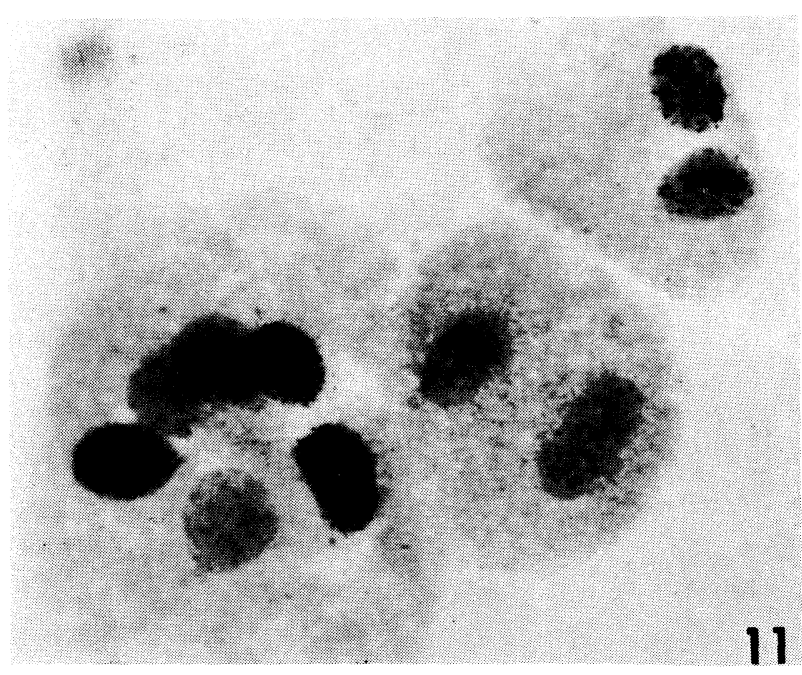

Fig. 11. Autoradiography of CB-induced multinucleate cells after exposure to ${ }^{3} \mathrm{H}-\mathrm{TdR}$ for 20 minutes. Two binucleate cells in which the nuclei involved are either labeled or unlabeled and one hexanucleate cell having heavily and lightly labeled and unlabeled nuclei. 
multinucleate and polyploid cells (Table 3, Fig. 11). The number of nuclei in multinucleate cells increased with time (Table 3 ). The nuclei of these cells were not always the same in size, especially in cells exposed for longer periods of time, which comprised of many overlapped and lobulated nuclei. The increased number of nuclei was often reflected in the occurrence of polyploid metaphases, some of which had more than 200 chromosomes. On the other hand, there were many metaphase cells containing PC (Figs. 12-15). The frequency of these cells increased with time after exposure to CB (Table 3). Of interest was the fact that normal metaphase chromosomes in the same cells were usually highly polyploid, and diploid metaphases were rarely coexisted with PC. The latter represented only 5 and $2.5 \%$ of the PC-bearing cells in the 2 and 4 day samples, respectively. In fact, the occurrence of PC was closely associated with that of polyploid metaphases which represent multinucleate cells in mitosis. In other words, PC was induced more frequently in cells having a higher number of nuclei.

In control cultures treated with $\mathrm{DMSO}$, at a concentration $(0.03 \%)$ equivalent to that used for the $\mathrm{CB}$ experiment, neither multinucleate and polyploid cells nor PC were induced.

Table 2. Autoradiographic patterns of BLM- and CB-induced PC after labeling with ${ }^{3} \mathrm{H}-\mathrm{TDR}$

\begin{tabular}{|c|c|c|c|c|c|c|c|c|c|}
\hline \multirow{3}{*}{$\begin{array}{c}\text { Types } \\
\text { of } \\
\text { PC }\end{array}$} & \multicolumn{3}{|c|}{ BLM experiments } & \multicolumn{6}{|c|}{$\mathrm{CB}$ experiments } \\
\hline & \multicolumn{2}{|c|}{ Continuous } & \multirow{2}{*}{ Total } & \multicolumn{2}{|c|}{ Pulse } & \multirow{2}{*}{ Total } & \multicolumn{2}{|c|}{ Continuous } & \multirow{2}{*}{ Total } \\
\hline & Labeled & Unlabeled & & Labele & Unlabeled & & Label & labeled & \\
\hline A & 0 & 23 & 23 & 6 & 4 & 10 & 17 & 1 & 18 \\
\hline B & 10 & 0 & 10 & 1 & 8 & 9 & 17 & 2 & 19 \\
\hline $\mathrm{C}$ & 21 & 35 & 56 & & & & & & \\
\hline $\mathrm{C} 1$ & & & & 25 & 17 & 42 & 30 & 2 & 32 \\
\hline $\mathrm{C} 2$ & & & & 8 & 0 & 8 & 10 & 0 & 10 \\
\hline
\end{tabular}

Autoradiographic study: Cells were treated with $\mathrm{CB}$ for 4 days and pulse-labeled with ${ }^{3} \mathrm{H}$-TdR for 20 minutes. There was a significant number of cells involving asynchronous nuclei, i.e., the cells having both labeled and unlabeled nuclei and those having nuclei with different grain densities (Fig. 11). A similar asynchrony of nuclear development in CB-induced multinucleate cells was observed by Krishan et al. (1969). The present study further demonstrated a tendency that the greater the number of nuclei involved in the same cell, the higher was the frequency of cells showing nuclear asynchrony; the frequencies of asynchrony being 5.7, 23.9 and $32.6 \%$ in bi-, tri- and tetranucleate cells, respectively. As high as $43 \%$ of the cells with more than 5 nuclei showed such an asychronous condition. This and the above finding that more PC was induced in highly polyploid cells support the view that the nuclear asynchrony is prerequisite for induction of $\mathrm{PC}$.

Comparing to the BLM-induced PC which originated from micronuclei, the CBinduced PC was larger in size. Hence the morphologic detail of PC in the latter system could be analyzed more easily. It was classified into four categories, types A, B, C1 
somes, but in others no such double structure was detected. Type B (Fig. 13) was the same as that defined in the BLM experiment. Type $\mathrm{Cl}$ (Fig. 14) was composed of chromatin particles of various sizes, some of which were apparently identified as chromosome fragments of paired chromatin particles. Occasionally, the chromosome fragments showed segmented appearance as seen in type B. Type C2 (Fig. 15) was the severest form including fine granules of chromatin or very thin chromatin threads without any detectable chromosome structure.

DNA synthetic patterns for those different types of PC were investigated by pulse (20 minutes) and continuous (2.5 hours) labelings with ${ }^{3} \mathrm{H}-\mathrm{TdR}$ (Table 2). Since the length of G2 phase in Don cells was about 2.5 hours, cells in both S and G2 phases were expected to be labeled by the latter method, while the former method could mark only cells in the $\mathrm{S}$ phase. As shown in Table 2, type B chromatin was labeled by continuous labeling, but not by pulse labeling, suggesting that this type of PC was derived from G2 nuclei. Type C2 seemed to represent the $\mathrm{S}$ phase chromatin, because it was labeled by both pulse and continuous labelings.

Types A and C1 consisted of both S and G2 chromatins, because either labeled or unlabeled chromatin was shown by the pulse labeling and the continous treatment yielded the label in most PC. However, careful comparison of these chromatins with their labeling patterns made possible to some extent the prediction of the nuclear phase from which the PC was derived. Thus, in type A the prophase-like chromosomes with apparent two chromatids were not labeled by pulsing with ${ }^{3} \mathrm{H}-\mathrm{TDR}$, but PC without such a double structure was well labeled in most instances. The former probably represents the $\mathrm{G} 2$ chromatin and the latter S. In type $\mathrm{C} 1$, the unlabeled $\mathrm{PC}$ by pulsing composed of more condensed chromosome fragments (Fig. 14) as compared to the labeled one (Fig. 16), suggesting the former being in G2 and the latter in S.

Unaffected metaphase chromosomes in the PC-bearing cells were either entirely labeled or only slightly labeled when exposed to ${ }^{3} \mathrm{H}-\mathrm{TDR}$ for 2.5 hours. The labeling index was $20.3 \%(16 / 75)$. In contrast, $53 \%$ (53/100) of the metaphase cells without PC were labeled, the incidence being equivalent to that expected from the normal G2 length (2.5 hours) of Don cells. The lowered incidence of labeling in the former may be a reflexion of the prolonged G2 period, since a similar phenomenon has been reported in virus-fused cells (Johnson and Rao 1971).

\section{DISCUSSION}

Nuclear asynchronization and PC induction: Multinucleate cells found in a wide variety of cells are usually synchronous with regard to the cell cycle of the nuclei (cf. Johnson and Rao 1971). However, the asynchrony in DNA synthesis and/or mitosis in multinucleate systems is no exception, as reported in several mammalian cell cultures (Sandberg et al. 1966; Kato and Sandberg 1967, 1968; Burns 1971). Spontaneous multinucleate cells occurring in some in vitro systems have been ascribed to possible virusmediated cellular fusion (Poste 1970) or to the nuclear division without cytokinesis (O'Neill and Miles 1971). The formation of micronuclei resulting from the division of telophase cells with lagging chromosomes or acentric fragments (Kato and Sandberg 


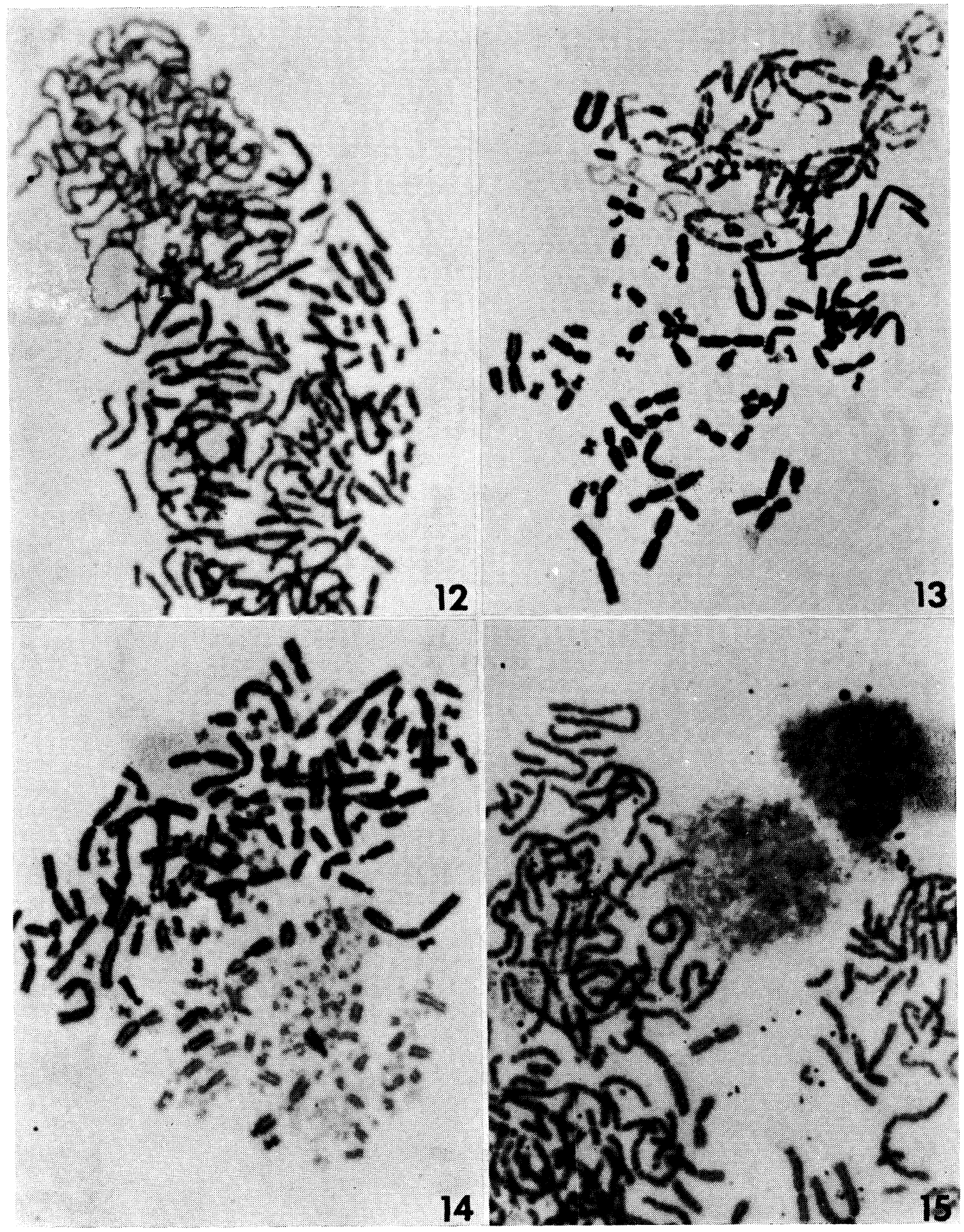

Figs. 12-15. Don metaphase cells with various types of PC produced by CB treatment $(1 \mu \mathrm{g} / \mathrm{ml})$ for 4 days. 12. Type A. 13. Type B. 14. Type C1. 15. Types $\mathrm{C} 2$ and $\mathrm{A}$. 

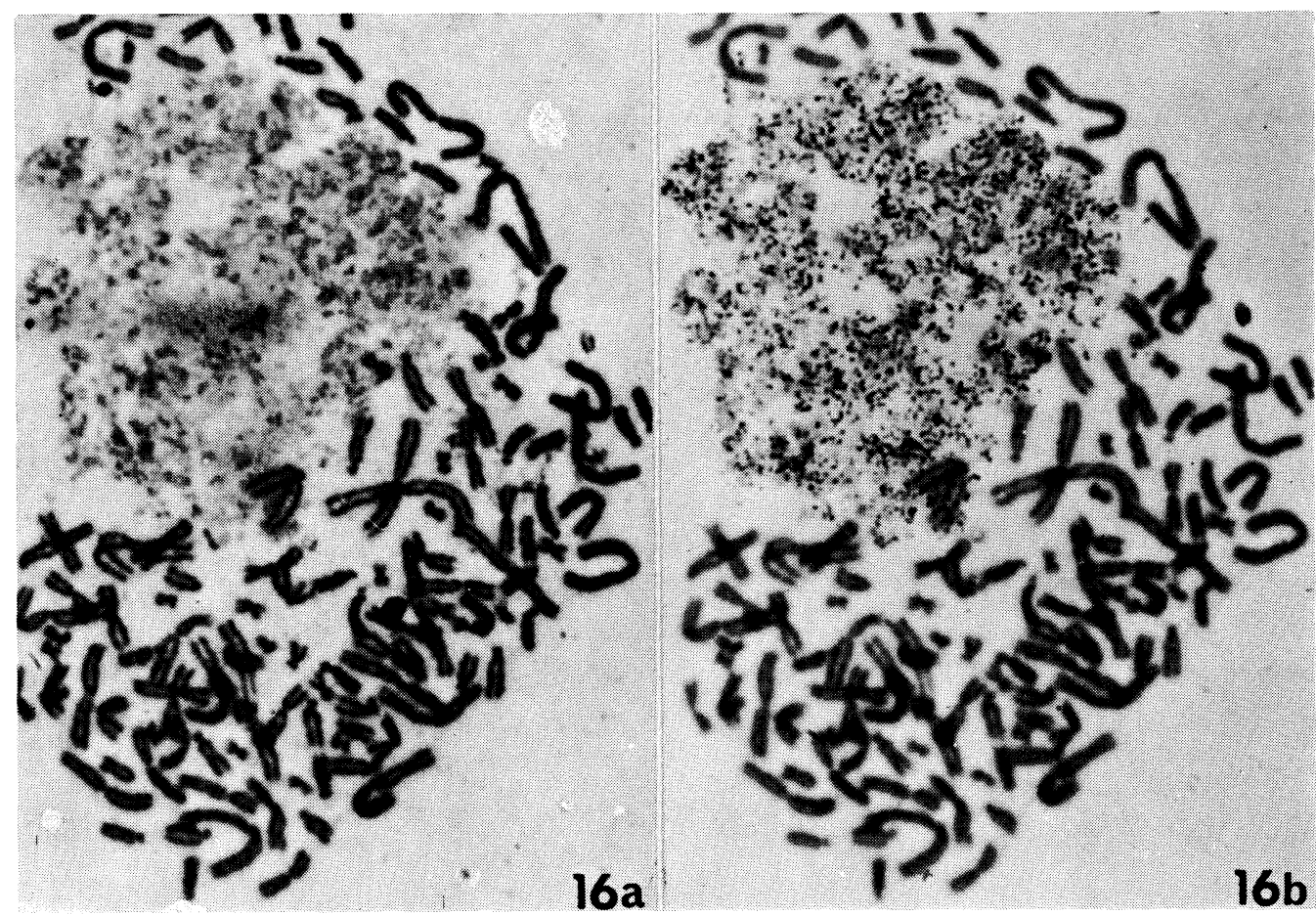

Fig. 16. Autoradiography of $\mathrm{CB}$-induced $\mathrm{PC}$ of type $\mathrm{C} 1$ after pulsing with ${ }^{3} \mathrm{H}-\mathrm{TdR}$ for 20 minutes. a) before autoradiography; b) after autoradiography.

and C2. Types A and B were the same figures as those described in the BLM experiment, while type $\mathrm{C}$ was subdivided into two types, $\mathrm{C} 1$ and $\mathrm{C} 2$.

type A (Figs. 12 and 15) was represented by homogeneously condensed chromatin threads as described before, but their width and length varied from cell to cell. In some cells two daughter chromatids were clearly visible, resembling prophase chromo-

Table 3. Frequencies of multinucleate cells, polyploid cells, and PC in Don cells after CB treatment $(1 \mu \mathrm{g} / \mathrm{ml})$

\begin{tabular}{|c|c|c|c|c|c|c|c|c|c|}
\hline \multirow{2}{*}{$\begin{array}{l}\text { Days } \\
\text { after CB } \\
\text { addition }\end{array}$} & \multicolumn{6}{|c|}{ No. of nuclei per cell } & \multirow{2}{*}{$\begin{array}{l}\text { Total } \\
\text { no. of } \\
\text { cells }\end{array}$} & \multirow{2}{*}{$\begin{array}{l}\text { Polyploid } \\
\text { cells } \\
(\%)^{2)}\end{array}$} & \multirow{2}{*}{$\begin{array}{c}\text { PC in poly } \\
\text { ploid cells } \\
(\%)^{3)}\end{array}$} \\
\hline & 1 & 2 & 3 & 4 & 5 & $5<1)$ & & & \\
\hline 0 & 283 & 10 & 5 & 2 & 0 & 0 & 300 & 3.0 & 0.0 \\
\hline 1 & 103 & 170 & 20 & 5 & 2 & 0 & 300 & 80.5 & 1.3 \\
\hline 2 & 156 & 82 & 33 & 18 & 6 & 5 & 300 & 78.0 & 4.1 \\
\hline 4 & 48 & 95 & 70 & 37 & 23 & 27 & 300 & 88.5 & 19.2 \\
\hline Control ${ }^{4)}$ & 278 & 19 & 2 & 0 & 0 & 1 & 300 & 2.5 & 0.0 \\
\hline
\end{tabular}

1) Exact counts were impossible because of overlapping and lobulation of nuclei in some cells.

2) Based on 200-300 metaphase cells.

3) Based on 60-200 polyploid metaphase cells.

4) This sample was prepared from cells treated with DMSO $(0.03 \%)$ for 4 days. 
1968) can also be considered as a multinucleation in a broader sence. The present study revealed the last two processes more clearly by the use of two chemicals, BLM and $\mathrm{CB}$, with more precise autoradiographic demonstration of asynchronous DNA synthesis and mitosis in such multinucleate systems.

Certain nucleo-cytoplasmic interactions have been suggested indispensable for the achievement of nuclear synchrony in multinucleate cells, and the nuclear asynchrony in large multinucleate cells was accounted for the possible uneven distribution of some cytoplasmic factors (Johnson and Rao 1971). This assumption may be supported by the fact that the higher the number of nuclei involved in the CB-induced multinucleates, the greater the asynchrony was induced. In the BLM-induced multinucleates, however, the size difference between the main nucleus and micronucleus could also cause the unbalanced nucleo-cytoplasmic relationship leading to asynchronization.

The present study disclosed that the formation of multinucleate cells and asynchronization of nuclei involved were intimately related to the induction of PC. There were three essential findings: 1) the induction of $\mathrm{PC}$ was preceded by the formation of micro- or multinucleate cells; 2) the PC figures, irrespective of their size and shape, always coexisted with normal metaphase chromosomes; and 3) asynchronous DNA synthesis was demonstrated between the PC and unaffected normal chromosomes. These results are in agreement with the previous studies dealing with spontaneously occurring (Kato and Sandberg 1967, 1968) and virus-induced multinucleate cells (Sandberg et al. 1970; Johnson and Rao 1971).

Morphologic variety of PC and the cell cycle: The close relationship of the types of PC to cellular cycle has been analyzed in Sendal virus-fused cells (Sandberg et al. 1970; Johnson and Rao 1970; Stenman and Saksela 1971). The general interpretation for the origin of PC may be put forward as in the followings on the basis of the present and other studies: The S phase nuclei tend to show relatively small chromatin particles (types $\mathrm{C}$ and $\mathrm{C} 1$ ) or very fine chromatin threads (type C2). Prophase-like chromosomes with double structure (type A) or paired chromatin particles of various sizes (type C1) apparently represent G2 nuclei. BLM-induced type A chromatin which was not labeled by the continuous exposure seems to be derived from G1 micronuclei. They are morphologically very similar to the affected G1 nuclei shown in virus-fused cells. CB-induced type A without visible double structure may also belong to this category, though some of them were apparently labeled by pulsing. Such labeled chromatin may probably be in the $\mathrm{S}$ phase close to G1.

Type B chromatin of unusually extended or segmented nature has not been detailed in virus-fused cells. The present labeling experiments revealed that they originated from G2 chromatin; they are possibly an intermediate form between the type A and type C1. Similar unusual figures of chromosomes have been described in metaphase plates of Chinese hamster cells after treatment with Colcemid (Stubblefield 1964), ${ }^{3} \mathrm{H}$ TdR (Ikeuchi et al. 1972) or 5-bromodeoxyuridine (Zakharov and Egolina 1972), as well as in several non-treated mammalian cell lines (Miles and O'Neill 1969; zur Hausen 1967). Considering that such segmented chromosomes were induced even in mononucleate cells (Zakharov and Egolina 1972), multinucleate condition may not always be necessary if there exists an adequate asynchrony within a cell. 
On the basis of the above data and consideration, the correlation between the types of PC and cellular phases is schematically illustrated in Fig. 17.

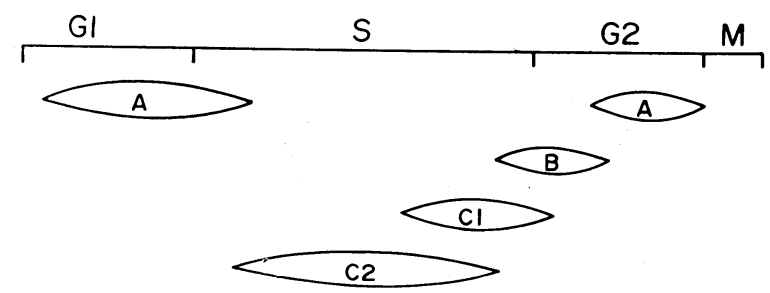

Fig. 17. Diagram representing the relationship between the types of $\mathrm{PC}$ and cellular phases in BLM- or CB-induced multinucleate cells. The extent to which each type of PC occupies in the cell cycle was estimated from labeling patterns with ${ }^{3} \mathrm{H}-\mathrm{TdR}$; and the overlapping of two different types of PC were based on the presence of an intermediate form between the two, as well as on their labeling patterns.

Concluding remarks: The present study emphasizes that the mechanism of PC induction by chemicals is essentially the same as that shown in virus-mediated cells. Here again the presence of metaphase nuclei is necessary for the induction of PC in interphase nuclei. The presence of virus is not necessarily the direct cause of PC, and the occurrence of PC is a common event in multinucleate systems with asynchronous nuclear cycle.

The chromatin change possibly relevant to the micronuclear PC was noted in cultured fibroblasts from Bloom's syndrome patients who showed an increased incidence of spontaneous chromosome breakages (German 1969). An unusual morphologic alteration reported in ring chromosomes in certain human lymphocyte cultures (Gripenberg 1967; Kistenmacher and Punnet 1970) may be explained by a similar mechanism. Furthermore, aberrant figures comparable to $\mathrm{PC}$ have been described in the meiotic process of some plants (Kihara and Lilienfeld 1934; Holden and Mota 1956).

As mentioned earlier, the phenomenon of "prophasing" represents the rapid morphological transformation of interphase nuclei to mitotic stage under the influence of a triggering effect of mitotic nuclei sharing a common cytoplasm. This can be inferred to a nuclear synchronization process, as seen between heterophasic interphase nuclei (Johnson and Rao 1971). As to the fate of PC in the subsequent mitotic cycles, two different processes have been conceived in Sendai virus-fused cells (Matsui et al. 1972b): one is reorganization of PC as intact chromosomes resulting in polyploid cells, and the other is micronuclear formation and reappearance as PC in the next mitosis. Rapid disintegration and loss of those aberrant chromatin after cell division are also possible, as suggested by some workers (Holden and Mota 1956; Gripenberg 1967; zur Hausen 1967), and the mechanism of chromosomal segregation in interspecific somatic cell hybrids may partly be attributed to such processes (Kao and Puck 1970; Rao and Johnson 1972; Yoshida 1972). Recent evidence of translocation or incorporation of small parts of PC to intact chromosomes (Matsui 1973) supports the earlier suggestion by Schwarz 
et al. (1971). Further studies are thus desirable to obtain a full account of the biological significance of PC in the progeny cells.

\section{SUMMARY}

Multinucleate condition was induced in Chinese hamster cells by treatments with bleomycin (BLM) and cytochalasin B (CB). BLM initially induced chromosome aberrations, such as breaks and reunions, and the resulting lagging chromosomes or acentric fragments formed micronuclei after cell division. $\mathrm{CB}$ inhibited cytokinesis, but not karyokinesis, which resulted multinucleate cells. In parallel with the appearance of the micronucleate or multinucleate interphase cells, there observed in metaphase cells "pulverized" or "prophased" chromatin (PC). Autoradiographic analyses revealed that nuclear asynchronization and subsequent asynchronous mitosis were prerequisite for the induction of $\mathrm{PC}$ in the interphase nuclei. Several characteristic morphologic features of PC were distinguishable depending on the different cell cycle of the affected interphase chromatin, $i$. $e$., the different degree of asynchrony between the mitotic and interphase nuclei.

\section{ACKNOWLEDGMENTS}

The author wishes to thank Prof. Motomichi Sasaki for his direction with invaluable advice and suggestion, and revision of the manuscript.

\section{LITERATURE CITED}

Arora, O.P., V.C. Shah, and S.R. V. Rao, 1969 Studies on micronuclei induced by mitomycin-C in the root cells of Vicia faba. Exp. Cell Res. 56: 443-448.

Aya, T., and A. A. Sandberg, 1971 Chromosome pulverization and RNA synthesis. J. Nat. Cancer Inst. 47: 961-969.

Burns, E. R., 1971 Synchronous and asynchronous DNA synthesis in multinucleated Ehrlich ascites tumor cells compared with multinucleated cells cultured from frog lung. Exp. Cell Res. 66: 152-156.

Carter, S. B., 1967 Effects of cytochalasins on mammalian cells. Nature 213: 261-264.

Das, N. K., 1962 Synthetic capacities of chromosome fragments correlated with their ability to maintain nucleolar material. J. Cell Biol. 15: 121-130.

German, J., 1969 Chromosomal breakage syndromes. In Birth Defects: Original Article Ser. 5: $117-131$.

Gripenberg, U., 1967 The cytological behavior of a human-ring chromosome. Chromosoma 20: 284-289.

Holden, J.W.H., and M. Mota, 1956 Non-synchronized meiosis in binucleate pollen mother cells of an Avena hybrid. Heredity 10: 109-117.

Ikeuchi, T., and A. A. Sandberg, 1970 Chromosome pulverization in virus-induced heterokaryons of mammalian cells from different species. J. Nat. Cancer Inst. 45: 951-963.

Ikeuchi, T., M. Sanbe, H. Weinfeld, and A. A. Sandberg, 1971 Induction of nuclear envelopes around metaphase chromosomes after fusion with interphase cells. J. Cell Biol. 51: 104-115.

Ikeuchi, T., H. Weinfeld, and A. A. Sandberg, 1972 Chromosome pulverization in micronuclei induced by tritiated thymidine. J. Cell Biol. 52: 97-104. 
Johnson, R. T., and P. N. Rao, 1970 Mammalian cell fusion: Induction of premature chromosome condensation in interphase nuclei. Nature 226: 717-722.

Johnson, R. T., and P. N. Rao, 1971 Nucleo-cytoplasmic interactions in the achievement of nuclear synchrony in DNA synthesis and mitosis in multinucleate cells. Biol. Rev. 56: 97-155.

Kao, F. T., and T. T. Puck, 1970 Genetics of somatic mammalian cells: Linkage studies with human-Chinese hamster cell hybrids. Nature 228: 329-332.

Kato, H., and A. A. Sandberg, 1967 Chromosome pulverization in human binucleate cells following Colcemid treatment. J. Cell Biol. 34: 35-45.

Kato, H., and A. A. Sandberg, 1968 Chromosome pulverization in human cells with micronuclei. J. Nat. Cancer Inst. 40: 165-179.

Kihara, H., and F. Lilienfeld, 1934 Kerneinwanderung und Bildung syndiploider Pollen-Mutterzellen bei dem F1-Bastard Triticum aegilopoides $\times$ Aegilops squarrosa. Japan. J. Genetics 10: $1-28$.

Kistenmacher, M. L., and H.H. Punnett, 1970 Comparative behavior of ring chromosomes. Amer. J. Hum. Genet. 22: 304-318.

Krishan, A., and R. Ray-Chaudhuri, 1969 Asynchrony of nuclear development in cytochalasininduced multinucleate cells. J. Cell Biol. 43: 618-621.

Matsui, S., H. Weinfeld, and A. A. Sandberg, 1971 Dependence of chromosome pulverization in virus-fused cells on events in the G2 period. J. Nat. Cancer Inst. 47: 401-411.

Matsui, S., H. Yoshida, H. Weinfeld, and A. A. Sandberg, 1972a Induction of prophase in interphase nuclei by fusion with metaphase cells. J. Cell Biol. 54: 120-132.

Matsui, S., H. Weinfeld, and A. A. Sandberg, 1972b Fate of chromatin of interphase nuclei subjected to "prophasing" in virus-fused cells. J. Nat. Cancer Inst. 49: 1621-1630.

Matsui, S., 1973 "Prophasing" as a possible cause of translocation in virus-fused cells. Nature New Biol. 243: 208-209.

Miles, C. P., and F. O'Neill, $1969{ }^{3} \mathrm{H}$ labeling patterns of permanent cell line chromosomes showing pulverization or accentuated secondary constrictions. J. Cell Biol. 40: 553-561.

Nichols, W. W., A. Levan, P. Aula, and E. Norrby, 1964 Extreme chromosome breakage induced by measles virus in different in vitro systems. Hereditas 51: 380-382.

O'Neill, F. J., 1972 Chromosome pulverization in cultured normal and neoplastic cells treated with cytochalasin B. J. Nat. Cancer Inst. 49: 1733-1738.

O'Neill, F. J., and C. P. Miles, 1971 Origin of nuclei in spontaneous HeLa cell chromosome pulverization. J. Nat. Cancer Inst. 46: 1085-1092.

Paika, K.D., and A. Krishan, 1973 Bleomycin-induced chromosomal aberrations in cultured mammalian cells. Cancer Res. 33: 961-965.

Poste, G., 1970 Virus-induced polykaryocytosis and the mechanism of cell fusion. Adv. Virus Res. 16: 303-356.

Rao, P.N., and R. T. Johnson, 1972 Premature chromosome condensation: A mechanism for the elimination of chromosomes in virus-fused cells. J. Cell Sci. 10: 495-513.

Sandberg, A. A., T. Sofuni, N. Takagi, and G. E. Moore, 1966 Chronology and pattern of human chromosome replication, IV. Autoradiographic studies of binucleate cells. Proc. Nat. Acad. Sci. 56: 105-110.

Sandberg, A. A., T. Aya, T. Ikeuchi, and H. Weinfeld, 1970 Definition and morphologic features of chromosome pulverization: A hypothesis to explain the phenomenon. J. Nat. Cancer Inst. 45: $615-623$.

Schwarz, A. G., P.R. Cook, and H. Harris, 1971 Correction of a genetic defect in a mammalian cell. Nature New Biol. 230: 5-8.

Stenman, S., 1971 Depression of RNA synthesis in the prematurely condensed chromatin of pulverized HeLa cells. Exp. Cell Res. 69: 372-376.

Stenman, S., and E. Saksela, 1971 The relationship of Sendai virus-induced chromosome pulverization to cell cyclus in HeLa cells. Hereditas 69: 1-14.

Stubblefield, E., 1964 DNA synthesis and chromosomal morphology of Chinese hamster cells cultured in media containing $\mathrm{N}$-deacetyl-N-methylcolchicine (Colcemid). In Cytogenetics of Cells in Culture (R. J. C. Harris, ed.) Acad. Press Inc., New York, Vol. 3, 223-248. 
Umezawa, H., M. Ishizuka, K. Maeda, and T. Takeuchi, 1967 Studies on Bleomycin. Cancer 20: 891-895.

Yoshida, M.C., 1972 A note on chromosome pulverization and nuclear fragmentation observed in a somatic mouse cell hybrid. Japan. J. Genetics 47: 447-449.

Zakharov, A.F., and N.A. Egolina, 1972 Differential spiralization along mammalian mitotic chromosomes. I. BUDR-revealed differentiation in Chinese hamster chromosomes. Chromosoma 38: $341-365$.

zur Hausen, H., 1967 Chromosomal changes of similar nature in seven established cell lines derived from the peripheral blood of patients with leukemia. J. Nat. Cancer Inst. 38: 683-696. 